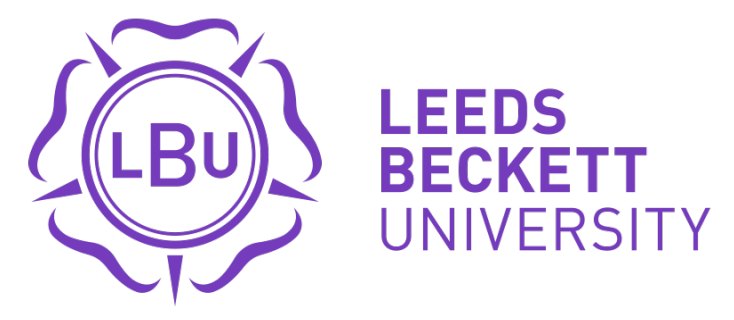

Citation:

Mazanov, J and Backhouse, SH and Connor, J and Hemphill, D and Quirk, F (2014) Athlete support personnel and anti-doping: Knowledge, attitudes, and ethical stance. Scandinavian journal of medicine \& science in sports, 24 (5). 846 - 856. ISSN 0905-7188 DOI: https://doi.org/10.1111/sms.12084

Link to Leeds Beckett Repository record:

https://eprints.leedsbeckett.ac.uk/id/eprint/152/

Document Version:

Article (Accepted Version)

The aim of the Leeds Beckett Repository is to provide open access to our research, as required by funder policies and permitted by publishers and copyright law.

The Leeds Beckett repository holds a wide range of publications, each of which has been checked for copyright and the relevant embargo period has been applied by the Research Services team.

We operate on a standard take-down policy. If you are the author or publisher of an output and you would like it removed from the repository, please contact us and we will investigate on a case-by-case basis.

Each thesis in the repository has been cleared where necessary by the author for third party copyright. If you would like a thesis to be removed from the repository or believe there is an issue with copyright, please contact us on openaccess@leedsbeckett.ac.uk and we will investigate on a case-by-case basis. 


\section{Athlete Support Personnel and Anti-Doping: Knowledge, Attitudes and Ethical Stance}

\section{Running Head: Athlete Support Personnel and Anti-Doping}

Jason Mazanov $^{1, *}$, Sue Backhouse ${ }^{2}$, James Connor ${ }^{1}$, Dennis Hemphill ${ }^{3}$ \& Frances Quirk $^{4}$

1 - School of Business, UNSW-Canberra, Australia

2 - Carnegie Faculty of Sport, Leeds Metropolitan University, United Kingdom

3 - School of Sport and Exercise Science, Victoria University, Australia

4 - School of Medicine and Dentistry, James Cook University, Australia

* Corresponding Author:

Jason Mazanov, PhD MAPS

School of Business

UNSW-Canberra

PO Box 7916

CANBERRA BC ACT 2610

Australia

P: +61 262688071

F: +61262688450

E: j.mazanov@adfa.edu.au 


\begin{abstract}
Athlete support personnel (ASP) failing to meet responsibilities under the World Anti-Doping Code risk sanction. It is unclear whether the poor knowledge of responsibilities seen in sports physicians and coaches applies to other ASP (e.g. administrators, chiropractors, family, nutritionists, physiotherapists, psychologists and trainers). A purposive sample of Australian ASP ( $n=292)$ responded to a survey on knowledge of anti-doping rules (35 true/false questions), ethical beliefs and practice, and attitudes towards performance enhancement. Some ASP declined to participate claiming doping was irrelevant to their practice. Physicians were the most knowledgeable (30.8/35), with family and trainers the least (26.0/35). ASP reported improvements were needed to support anti-doping education (e.g. basis for anti-doping) and practice (e.g. rules). ASP also had a slightly negative attitude towards performance enhancement. Linear regression showed being a sports physician, providing support at the elite level, and 15 years experience influenced knowledge. The results confirm gaps in knowledge, and suggest more effort is needed to engage with ASP anti-doping education and practice. Examining physician and elite level ASP acquisition of knowledge may be a way forward. Future work on the context within which ASP experience anti-doping is needed, exploring acquisition and translation of knowledge into practice.
\end{abstract}

Key words: Anti-Doping; Athlete Support Personnel; Knowledge; Attitudes; Ethics; Education; Australia 


\section{Introduction}

The World Anti-Doping Code (WADC) serves to protect the "Athletes' fundamental right to participate in doping-free sport" and to ensure "harmonised, coordinated and effective antidoping programs at the international and national level" (WADA, 2009, p.1). The overall emphasis on promoting 'pure sport' appears to be supported by the stakeholder community as this section remains unchanged in the 2015 update to the Code (WADA, 2012). Similarly, the role of athlete support personnel (ASP) in anti-doping efforts is consolidated in the 2015 update (WADA, 2012) following the formalisation of this role in 2009. The formalised role in anti-doping flows from empirical and anecdotal evidence that ASP have significant influence in athlete decisions to dope or abstain (Mazanov \& Huybers, 2010; Smith \& Stewart, 2008), such that doping requires 'an entire athletic community - athletes trainers, physicians, and officials' (Hoberman, 2001, p. 264). Indeed, the Dubin (1990) report highlighted the extensive cast and crew involved in doping in Canada in the late 80s and three decades later the US Anti-Doping Agency case against Lance Armstrong has once again brought to light a lengthy list of supporting actors (USADA, 2012a).

As a result, the 2009 WADC update included sanctions (up to life bans) for ASP found to have committed an anti-doping rule violations (ADRV) under Articles 2.4-2.8. The 2015 update shows no indication of a leniency in these sanctions (WADA, 2012). Article 2.8 establishes that ASP can be sanctioned for "administration, attempted administration, assistance, encouragement, aiding, abetting, covering up, or any other type of complicity involving an attempted or actual ADRV" (WADA, 2009, p. 25). Mazanov et al. (2009) express concern over Article 2.8, arguing that its breadth and ambiguity make it difficult for ASP to know exactly what constitutes a violation. For example, it is unclear how or even whether a prosecution would unfold where a parent supplies their child with a prohibited substance (e.g. pseudo-ephedrine or beta-agonists).

Yet, high profile cases of athlete support personnel (ASP) being sanctioned for their role in athlete doping demonstrates that the obligations of ASP are taken seriously by national anti-doping organisations. According to the WADC, an ASP is "any coach, trainer, manager, agent, team staff, official, medical, paramedical personnel, parent or any other person working with, treating or assisting an athlete participating in or preparing for sports competition" (WADA, 2009, p. 128). Three ASP from the US Postal Service cycling team (two physicians and a sports trainer) were given lifetime bans for possession, trafficking, 
administering, aiding and covering up athlete doping (USADA, 2012b). A track and field coach (and 100m finalist at the Seoul Olympics) was given a lifetime ban for trafficking and administering prohibited substances (USADA, 2010). A player agent was given a10 year ban for their role in the BALCO scandal (USADA, 2011). The former chief executive and an assistant coach of the Hull Rugby League Football Club were banned for conspiring to cover up doping by one of the club's players (UK Anti-Doping, 2011). A Canadian sports trainer was given a 5 year ban for supplying a banned diuretic to a 16 year old athlete competing at the national tae kwon do championships (CCES, 2012). With such serious consequences, ASP must be knowledgeable about the overarching aim of the WADC and be familiar with their responsibilities under this Code (Mazanov, 2010).

The WADC also defines the responsibilities of ASP under Article 21.2 (WADA, 2009, p. 113). Here, the onus is on the ASP to be aware of and comply with anti-doping responsibilities (21.2.1), co-operate with athlete testing (21.2.2) and use their influence to foster anti-doping attitudes in athletes (21.2.3). In effect, these Articles suggest a "strict liability" approach to education for ASP (cf Amos \& Fridman, 2012). In simple terms, ignorance is no excuse in the context of the WADC mandated role for ASP. Therefore, in order to comply with the WADC and its aim to promote doping-free sport, and to avoid penalties associated with non-compliance, it is important to gauge the extent to which ASP are knowledgeable about the WADC and able to fulfil their responsibilities under it. Current research suggests that the limited anti-doping knowledge base for sports physician (Backhouse \& McKenna, 2011) and coaches (Backhouse \& McKenna, 2012) leaves them vulnerable to sanction. It remains to be seen whether this is true of other ASP, such as physiotherapists or sports trainers.

Thus, the aim of the current project was to determine the knowledge, ethical stance, and attitudes of ASP in relation to their anti-doping obligations. A purposive sample of the ASP groups that have obligations under the WADC were approached to participate, including administrators, chiropractors, coaches, dieticians, nutritionists, parents, physiotherapists, psychologists, sports physicians and sports trainers. Knowledge was assessed by adapting UK Sport "true-false" questions assessing athlete knowledge of anti-doping (Mazanov et al., 2009). Frequency and perceived ethicality of ASP anti-doping activity was measured by adapting Dawson et al.'s (2001) assessment of Victorian fitness practitioners' ethical behaviour. Attitude was measured using Petroczi \& Aidman's (2009) performance enhancing attitude measure. Given the exploratory nature of the research, no hypotheses are offered for 
the absolute level of knowledge, ethical stance or attitude, nor the magnitude or direction of differences between ASP groups.

\section{Method}

\section{Sampling Strategy}

Following ethical review and approval by the University of New South Wales Human Research Ethics Committee, surveys were distributed to delegates at the 2009 Australian Conference of Science and Medicine in Sport delegates and members of national sports bodies in Australia. The national sports bodies included government (e.g. sports institutes and academies) and professional organisations (representing chiropractors, dieticians, nutritionists, psychologists, sports physicians and sports trainers). Some peak bodies declined to distribute the survey as they felt the content of the survey was irrelevant to members. This sentiment was reflected at the Conference, where low return rates were explained by delegates as the perceived irrelevance of anti-doping to their ASP role.

The sampling strategy yielded $n=52$ returns from the Conference and $n=240$ from peak sports bodies, delivering a non-representative self-selected convenience sample. The sample is biased towards ASP who completed the survey on the basis anti-doping was relevant to them and they took an active interest in this aspect of sport. For example, 97.5\% of respondents indicated it is the responsibility of ASP to be aware of their obligations under the WADC. Survey responses should therefore be taken as the right tail of the distribution, with population scores occurring to the left of those reported in the Results. For example, with the sample theoretically biased towards a higher level of knowledge about anti-doping, ASP population knowledge is likely to be lower than the scores reported below.

\section{Sample Characteristics}

Of the $n=292$ responses, $n=93$ provided incomplete data sets where at least one section was missing data (68.2\% completion rate) leading to different sample sizes across the survey. Where possible the valid sample is reported; this is largely with single item analysis. Where no sample size is reported, the full sample of $n=292$ responded to that item. Where analysis examines the relationship between variables casewise omission is followed.

The sample was approximately balanced for gender (54\% male) with an average age of 40.2 years $(\mathrm{SD}=13.5, \mathrm{n}=287)$ and 16.8 years $(\mathrm{SD}=21.8$ years) experience in an athlete support role. Just over $44 \%$ were former elite athletes. 


\section{Survey Instrument}

The survey comprised of five main sections. The first section contained questions about demographic information, including age, gender, support role and time in that support role. Main sport was omitted as support personnel may provide support across a number of sports (e.g. physiotherapists, nutritionists and psychologists) and ethical review raising the possibility that identifying the sport may identify individuals. For example, a respondent nominating as a male Olympic archery coach of a particular age could identify that individual.

The second section included questions about the content knowledge of the WADC, replicating the five question true-false format used by UK Sport (see Mazanov et al, 2009) revised for the 2009 update to the WADC. The topic areas were prohibited substances and methods, sample collection rules, ADRV, athlete rights and responsibilities, nutritional supplements (e.g. application of WADC to supplements) and substance/method prohibition process (e.g. substance/method risks athlete health). A section on ASP obligations was also introduced (e.g. ASP can be banned for life for doping possession). Scores out of five were taken for each of the seven facets tested along with an aggregate score out of 35 .

The third section contained questions about the frequency (five point scale, "never" to "often") and ethicality (five point scale, "sound" to "unsound") of ASP behaviours in relation to anti-doping, based on an adaptation of Dawson et al. (2001). The complete list of items is available in Tables 3 and 4. A significant number of respondents discontinued at the start of or during the frequency and ethicality questions, or skipped these questions going to the fourth section. The fourth section assessed respondent attitude towards doping in sport using the Performance Enhancing Attitude Scale (Petroczi \& Aidman, 2009).

\section{Results}

Results are reported using descriptive statistics in the first instance. Aggregate analysis by ASP group uses one-way Analysis of Variance (ANOVA) or Kruskal-Wallis tests.

\section{Incompletes Analysis}

Incomplete responses $(\mathrm{n}=93)$ were equally distributed by gender $(57.0 \%$ male; $95 \mathrm{CI}$ (43.7, $63.3)$ ), were younger (36.1 vs. 42.2 ; $95 \mathrm{CI}(-9.6,-2.5))$ and while statistically equivalent in years of support provided $(20.3$ vs. 15.1 ; $95 \mathrm{CI}(-1.2,11.5))$ tended to being more experienced. 
Completion rate by support role and highest level of support shows the lowest completion rate was seen among family members and coaches supporting athletes at the junior elite level. Sports physicians and sports trainers had the highest completion rates. Younger (but potentially experienced) junior elite coaches or family members typically defined the demographic of the lowest completion rates.

\section{Knowledge}

Following case-wise deletion of missing data (valid $n=142$ ), knowledge was assessed for all seven facets and total knowledge scores across the seven categories by support role (see Table 1) were computed. The very low samples sizes that made up some cells (e.g. dieticians/nutritionists, soft tissue therapists and chiropractors) mean the results should be interpreted with caution. Differences between support roles were observed $\left(\mathrm{F}_{8,133}=6.17\right.$, $\mathrm{p}<0.001, \omega^{2}=0.23$ ). Post-hoc testing (Tukey’s HSD) indicated relatively lower knowledge among family members, sports trainer and nutritionists, with sports physicians demonstrating the highest level of knowledge. Across the test items, respondents were strongest in identifying what constituted an ADRV (86\% to 96\%). By comparison, all support roles did noticeably worse on the obligations of a support person under the WADC, ranging from $54 \%$ to $72 \%$.

Table 1: Average number of WADC test items correct by support role

\begin{tabular}{|c|c|c|c|c|c|c|c|c|}
\hline $\begin{array}{l}\text { Support } \\
\text { Role (n) }\end{array}$ & $\begin{array}{l}\text { Prohibited } \\
\text { Subst/Method }^{1}\end{array}$ & $\begin{array}{l}\text { Sample } \\
\text { Collection }^{1}\end{array}$ & ADRV $^{1}$ & $\begin{array}{l}\text { Athlete } \\
\text { Rights }\end{array}$ & $\begin{array}{l}\text { Nutritional } \\
\text { Supplements }\end{array}$ & $\begin{array}{l}\text { Prohibition } \\
\text { Process }^{1}\end{array}$ & $\begin{array}{l}\text { Support } \\
\text { Person } \\
\text { Obligations }\end{array}$ & Total $^{2}$ \\
\hline $\begin{array}{l}\text { Coach } \\
(28)\end{array}$ & $3.9(0.9)$ & $3.9(0.9)$ & $\begin{array}{l}4.6 \\
(0.6)\end{array}$ & $\begin{array}{l}4.1 \\
(0.8)\end{array}$ & $4.3(0.9)$ & $3.8(0.8)$ & $3.0(0.7)$ & $\begin{array}{l}27.5 \\
(2.3)\end{array}$ \\
\hline $\begin{array}{l}\text { Diet/Nutr } \\
\text { (7) }\end{array}$ & $4.2(1.0)$ & $3.6(1.1)$ & $\begin{array}{l}4.5 \\
(0.5)\end{array}$ & $\begin{array}{l}4.1 \\
(1.2)\end{array}$ & $4.1(1.2)$ & $4.1(0.9)$ & $3.1(1.3)$ & $\begin{array}{l}26.6 \\
(4.1)\end{array}$ \\
\hline $\begin{array}{l}\text { Family } \\
\text { (11) }\end{array}$ & $3.3(1.0)$ & $3.7(1.1)$ & $\begin{array}{l}4.4 \\
(0.7)\end{array}$ & $\begin{array}{l}3.8 \\
(0.8)\end{array}$ & $3.8(0.7)$ & $4.1(0.3)$ & $2.7(0.7)$ & $\begin{array}{l}26.0 \\
(1.9)\end{array}$ \\
\hline $\begin{array}{l}\text { Soft } \\
\text { Tissue } \\
\text { (9) }\end{array}$ & $4.0(1.0)$ & $3.7(0.9)$ & $\begin{array}{l}4.4 \\
(0.7)\end{array}$ & $\begin{array}{l}4.4 \\
(0.9)\end{array}$ & $4.3(0.5)$ & $4.2(0.7)$ & $2.9(0.9)$ & $\begin{array}{l}28.0 \\
(2.4)\end{array}$ \\
\hline $\begin{array}{l}\text { Trainer } \\
\text { (26) }\end{array}$ & $3.7(0.9)$ & $3.9(0.9)$ & $\begin{array}{l}4.3 \\
(0.7)\end{array}$ & $\begin{array}{l}3.8 \\
(1.1)\end{array}$ & $3.7(1.0)$ & $4.0(0.6)$ & $3.1(1.0)$ & $\begin{array}{l}26.1 \\
(2.5)\end{array}$ \\
\hline $\begin{array}{l}\text { Admin } \\
\text { (21) }\end{array}$ & $4.1(1.0)$ & $3.8(0.9)$ & $\begin{array}{l}4.7 \\
(0.6)\end{array}$ & $\begin{array}{l}4.0 \\
(1.2)\end{array}$ & $4.5(0.7)$ & $3.7(0.5)$ & $3.3(0.9)$ & $\begin{array}{l}27.7 \\
(3.6)\end{array}$ \\
\hline $\begin{array}{l}\text { Physician } \\
\text { (22) }\end{array}$ & $4.6(0.6)$ & $4.4(0.6)$ & $\begin{array}{l}4.8 \\
(0.4)\end{array}$ & $\begin{array}{l}4.5 \\
(0.6)\end{array}$ & $4.6(0.6)$ & $4.2(0.5)$ & $3.5(0.9)$ & $\begin{array}{l}30.8 \\
(1.6)\end{array}$ \\
\hline $\begin{array}{l}\text { Psych } \\
\text { (13) }\end{array}$ & $4.2(0.7)$ & $3.6(1.0)$ & $\begin{array}{l}4.4 \\
(0.8)\end{array}$ & $\begin{array}{l}4.2 \\
(1.1)\end{array}$ & $4.5(0.7)$ & $3.9(0.3)$ & $3.3(0.8)$ & $\begin{array}{l}28.1 \\
(2.4)\end{array}$ \\
\hline Chiro (5) & $3.6(0.9)$ & $3.6(0.9)$ & $\begin{array}{l}4.8 \\
(0.4)\end{array}$ & $\begin{array}{l}4.4 \\
(0.5)\end{array}$ & $4.0(1.0)$ & $4.0(0.0)$ & $3.6(0.5)$ & $\begin{array}{l}28.0 \\
(1.2)\end{array}$ \\
\hline Total & $4.0(0.9)$ & $3.9(0.9)$ & $\begin{array}{l}4.5 \\
(0.6)\end{array}$ & $\begin{array}{l}4.1 \\
(0.9)\end{array}$ & $4.2(0.8)$ & $4.0(0.6)$ & $3.1(0.9)$ & $\begin{array}{l}27.7 \\
(2.9)\end{array}$ \\
\hline
\end{tabular}




\section{Ethicality and anti-doping related behaviours}

As noted above, this section was completed by a sub-sample of respondents $(n=170-182$ respondents for behaviours and $n=156-161$ for ethicality). The distributions of responses and valid sample sizes for items related to doping are reported in Table 2 and beliefs around ethicality in Table 3. To simplify reporting and interpretation of results percentages are aggregated to create binomial data on the basis of presence or absence. For example, comparing "never" with other responses indicates when behaviour is displayed. Assessing practice as anything other than ethically "unsound" indicates respondents believe a case may make the practice sound. This style of aggregation has precedence in doping research where athletes reporting anything other than a "definitely no" response to future doping intentions indicates vulnerability to doping (Gucciardi et al., 2010).

Table 2: Athlete support personnel doping related behaviours

\begin{tabular}{|c|c|c|c|c|c|c|}
\hline Item & Never & Rarely & Sometimes & $\begin{array}{l}\text { Fairly } \\
\text { Often }\end{array}$ & Often & $\mathbf{N}$ \\
\hline $\begin{array}{l}\text { Advise about AD without } \\
\text { reading WADC }\end{array}$ & $72.9 \%$ & $18.8 \%$ & $6.1 \%$ & $0.6 \%$ & $1.7 \%$ & 181 \\
\hline $\begin{array}{l}\text { Little/no support to new ASP } \\
\text { wrt AD }\end{array}$ & $61.1 \%$ & $19.4 \%$ & $12.6 \%$ & $2.9 \%$ & $4.0 \%$ & 175 \\
\hline $\begin{array}{l}\text { Ignore unethical behaviour of } \\
\text { other ASP }\end{array}$ & $68.5 \%$ & $21.3 \%$ & $6.7 \%$ & $1.7 \%$ & $1.7 \%$ & 178 \\
\hline $\begin{array}{l}\text { Claim other ASP get athlete } \\
\text { performance by PED }\end{array}$ & $93.3 \%$ & $5.6 \%$ & $0.6 \%$ & $0.6 \%$ & $0.0 \%$ & 179 \\
\hline $\begin{array}{l}\text { Refuse work with athlete with } \\
\text { ADRV }\end{array}$ & $73.5 \%$ & $11.2 \%$ & $6.5 \%$ & $1.2 \%$ & $7.6 \%$ & 170 \\
\hline $\begin{array}{l}\text { Reporting ASP complicit in } \\
\text { ADRV }\end{array}$ & $73.7 \%$ & $9.1 \%$ & $6.9 \%$ & $1.7 \%$ & $8.6 \%$ & 175 \\
\hline $\begin{array}{l}\text { Advising athlete about } \mathrm{AD} \\
\text { without training in } \mathrm{AD}\end{array}$ & $68.7 \%$ & $16.8 \%$ & $11.7 \%$ & $1.1 \%$ & $1.7 \%$ & 179 \\
\hline $\begin{array}{l}\text { Working with athletes who } \\
\text { think doping is okay }\end{array}$ & $87.7 \%$ & $10.6 \%$ & $1.1 \%$ & $0.0 \%$ & $0.6 \%$ & 179 \\
\hline $\begin{array}{l}\text { Dietary advice without } \\
\text { training in nutrition }\end{array}$ & $60.4 \%$ & $21.4 \%$ & $13.2 \%$ & $2.7 \%$ & $2.2 \%$ & 182 \\
\hline $\begin{array}{l}\text { Putting pressure on athlete to } \\
\text { use PED to retain sponsor }\end{array}$ & $97.8 \%$ & $1.7 \%$ & $0.0 \%$ & $0.0 \%$ & 0.6 & 180 \\
\hline $\begin{array}{l}\text { Working with athlete who } \\
\text { uses anabolic steroids }\end{array}$ & $91.8 \%$ & $5.5 \%$ & $2.2 \%$ & $0.0 \%$ & $0.5 \%$ & 182 \\
\hline $\begin{array}{l}\text { Reporting athlete who is } \\
\text { doping }\end{array}$ & $76.9 \%$ & $11.0 \%$ & $1.7 \%$ & $2.3 \%$ & $8.1 \%$ & 173 \\
\hline $\begin{array}{l}\text { Discussing athlete doping } \\
\text { with other ASP }\end{array}$ & $77.3 \%$ & $14.4 \%$ & $6.1 \%$ & $1.1 \%$ & $1.1 \%$ & 181 \\
\hline $\begin{array}{l}\text { Encourage PED to facilitate } \\
\text { recovery from injury }\end{array}$ & $96.1 \%$ & $2.1 \%$ & $0.3 \%$ & $0.0 \%$ & $0.0 \%$ & 178 \\
\hline $\begin{array}{l}\text { Publicly claiming to support } \\
\text { AD }\end{array}$ & $28.2 \%$ & $7.9 \%$ & $18.6 \%$ & $16.9 \%$ & $28.2 \%$ & 177 \\
\hline $\begin{array}{l}\text { Discussing athlete doping } \\
\text { with other athletes }\end{array}$ & $90.6 \%$ & $6.6 \%$ & $1.7 \%$ & $0.6 \%$ & $0.6 \%$ & 181 \\
\hline $\begin{array}{l}\text { Encouraging athletes to be } \\
\text { good role models }\end{array}$ & $3.8 \%$ & $1.1 \%$ & $14.8 \%$ & $23.1 \%$ & $57.1 \%$ & 182 \\
\hline $\begin{array}{l}\text { Asking for testimonials about } \\
\text { your support for } \mathrm{AD}\end{array}$ & $80.9 \%$ & $10.1 \%$ & $9.0 \%$ & $0.0 \%$ & $0.0 \%$ & 178 \\
\hline
\end{tabular}


Table 2 corroborates role expectations such as encouraging athletes to be good role models. Some results can be explained by the rarity of behaviour, such as the low proportion reporting ASP complicit in an ADRV or reporting an athlete who is doping. There were some unexpected results. Firstly, 31.5\% (aggregated across "rarely" to "often") indicated they have ignored unethical behaviour of other ASP. In relation to doping specifically, $27.1 \%$ of respondents reported they have advised athletes about anti-doping without reading the WADC. There appears to be a minority of ASP who advise on anti-doping activities $(31.3 \%)$ and drug testing (19.6\%) without training, which extends to providing dietary advice (supplements) without proper training (39.6\%). There appeared to be a group of ASP who see little or no support to new colleagues with regards to anti-doping obligations (38.9\%). Some $77.3 \%$ indicated they "never" talk about athlete doping with other ASP. Of note, 96.1\% would "never" encourage an athlete to use a performance enhancing drug to facilitate recovery from injury. Finally, respondents were variable in their public declaration of support for anti-doping. While $71.8 \%$ had made some public declaration of their support for anti-doping, a minority of $28.2 \%$ have "never" made such a public statement.

Kruskal-Wallis testing of behaviour items indicated other distributional variation by support role type $(\mathrm{p}<0.05)$. Rates are reported as presence (aggregate of "rarely" to "very often") of behaviour. There was a lot more support for new ASP among psychologists (4/8) and a lot less for family or friends (1/16), physiotherapists (2/10) and sports administrators (7/29). Sports psychologists appeared to be more likely to work with athletes who think doping is okay (4/8), although this result may be a function of the small sample of sports psychologists. Coaches (32/62), family and friends (8/18), trainers (14/33) and sports physicians (4/6) were providing untrained dietary advice far more than psychologists (2/8) and, unsurprisingly, nutritionists (0/7). Sports physicians (2/6) and psychologists $(3 / 8)$ were more likely to work with athletes who use anabolic steroids compared with other support roles (5-15\%). Family and friends (0/16) and psychologists (0/8) had never reported athletes who dope, with sports physicians indicating more frequent reporting (4/6). The balance of roles reported $25-30 \%$ had experience with reporting athlete doping. Kruskal-Wallis testing showed public admission of support for anti-doping was less common among sports trainers (17/33) and psychologists (3/8). All sports physicians reported a declaration of support (6/6). 
Table 3: Athlete support personnel doping related beliefs about the ethicality of behaviour

\begin{tabular}{|c|c|c|c|c|c|c|}
\hline Item & Unsound & $\begin{array}{l}\text { Uns'nd, } \\
\text { Ex. }\end{array}$ & Sometimes & Sound, Ex. & Sound & $\mathbf{n}$ \\
\hline $\begin{array}{l}\text { Advise about AD without } \\
\text { reading WADC }\end{array}$ & $71.9 \%$ & $15.0 \%$ & $11.3 \%$ & $0.6 \%$ & $1.3 \%$ & 160 \\
\hline $\begin{array}{l}\text { Little/no support to new ASP } \\
\text { wrt AD }\end{array}$ & $76.3 \%$ & $13.1 \%$ & $6.9 \%$ & $1.9 \%$ & $1.9 \%$ & 160 \\
\hline $\begin{array}{l}\text { Ignore unethical behaviour of } \\
\text { other ASP }\end{array}$ & $82.0 \%$ & $10.6 \%$ & $5.6 \%$ & $1.9 \%$ & $0.0 \%$ & 161 \\
\hline $\begin{array}{l}\text { Claim other ASP get athlete } \\
\text { performance by PED }\end{array}$ & $88.1 \%$ & $9.4 \%$ & $2.5 \%$ & $0.0 \%$ & $0.0 \%$ & 159 \\
\hline $\begin{array}{l}\text { Refuse work with athlete with } \\
\text { ADRV }\end{array}$ & $23.8 \%$ & $15.6 \%$ & $25.6 \%$ & $20.6 \%$ & $14.4 \%$ & 160 \\
\hline $\begin{array}{l}\text { Reporting ASP complicit in } \\
\text { ADRV }\end{array}$ & $11.3 \%$ & $6.3 \%$ & $8.8 \%$ & $21.9 \%$ & $51.3 \%$ & 160 \\
\hline $\begin{array}{l}\text { Advising athlete about } \mathrm{AD} \\
\text { without training in } \mathrm{AD}\end{array}$ & $58.5 \%$ & $17.0 \%$ & $21.4 \%$ & $1.9 \%$ & $1.3 \%$ & 159 \\
\hline $\begin{array}{l}\text { Working with athletes who } \\
\text { think doping is okay }\end{array}$ & $73.8 \%$ & $13.8 \%$ & $10.6 \%$ & $1.3 \%$ & $0.6 \%$ & 160 \\
\hline $\begin{array}{l}\text { Dietary advice without } \\
\text { training in nutrition }\end{array}$ & $55.3 \%$ & $23.6 \%$ & $18.6 \%$ & $2.5 \%$ & $0.0 \%$ & 161 \\
\hline $\begin{array}{l}\text { Putting pressure on athlete to } \\
\text { use PED to retain sponsor }\end{array}$ & $98.1 \%$ & $0.6 \%$ & $1.2 \%$ & $0.0 \%$ & $0.0 \%$ & 161 \\
\hline $\begin{array}{l}\text { Working with athlete who } \\
\text { uses anabolic steroids }\end{array}$ & $82.3 \%$ & $12.7 \%$ & $2.5 \%$ & $1.9 \%$ & $0.6 \%$ & 158 \\
\hline $\begin{array}{l}\text { Reporting athlete who is } \\
\text { doping }\end{array}$ & $5.7 \%$ & $2.5 \%$ & $6.9 \%$ & $17.6 \%$ & $67.3 \%$ & 159 \\
\hline $\begin{array}{l}\text { Discussing athlete doping } \\
\text { with other ASP }\end{array}$ & $53.8 \%$ & $16.3 \%$ & $23.1 \%$ & $4.4 \%$ & $2.5 \%$ & 160 \\
\hline $\begin{array}{l}\text { Encourage PED to facilitate } \\
\text { recovery from injury }\end{array}$ & $84.2 \%$ & $10.6 \%$ & $3.2 \%$ & $0.6 \%$ & $1.6 \%$ & 158 \\
\hline Publicly claiming support AD & $19.5 \%$ & $1.9 \%$ & $7.5 \%$ & $13.8 \%$ & $57.2 \%$ & 159 \\
\hline $\begin{array}{l}\text { Discussing athlete doping } \\
\text { with other athletes }\end{array}$ & $81.9 \%$ & $11.3 \%$ & $5.0 \%$ & $1.3 \%$ & $0.6 \%$ & 160 \\
\hline $\begin{array}{l}\text { Encouraging athletes to be } \\
\text { good role models }\end{array}$ & $3.8 \%$ & $0.6 \%$ & $4.4 \%$ & $6.9 \%$ & $84.4 \%$ & 160 \\
\hline $\begin{array}{l}\text { Asking for testimonials about } \\
\text { your support for AD }\end{array}$ & $40.5 \%$ & $9.2 \%$ & $29.4 \%$ & $12.4 \%$ & $8.5 \%$ & 153 \\
\hline $\begin{array}{l}\text { Making unverified claims } \\
\text { about PE supplements }\end{array}$ & $93.1 \%$ & $6.3 \%$ & $0.6 \%$ & $0.0 \%$ & $0.0 \%$ & 160 \\
\hline $\begin{array}{l}\text { Accusing athletes of doping } \\
\text { with family/friends }\end{array}$ & $78.0 \%$ & $11.3 \%$ & $7.5 \%$ & $1.9 \%$ & $1.3 \%$ & 159 \\
\hline $\begin{array}{l}\text { Advising athletes about drug } \\
\text { testing without training }\end{array}$ & $65.6 \%$ & $17.5 \%$ & $15.6 \%$ & $1.3 \%$ & $0.0 \%$ & 160 \\
\hline $\begin{array}{l}\text { Advising athletes working } \\
\text { with other ASP about doping }\end{array}$ & $50.9 \%$ & $16.4 \%$ & $14.5 \%$ & $5.0 \%$ & $13.2 \%$ & 159 \\
\hline
\end{tabular}

A similar pattern emerged in Table 3 with regards to the ethicality of behaviours. Some behaviour was almost universally unacceptable, such as pressuring an athlete to dope to retain sponsorship (98.1\%). A minority (23.7\%) appeared to think that there are circumstances that make ignoring unethical behaviour of other ASP acceptable. This combined with $48.7 \%$ of respondents indicating there are ethical exceptions to reporting ASP complicit in an ADRV. Approximately $32.7 \%$ indicated there were exceptions to reporting athlete doping being ethically sound, although a minority (5.7\%) saw it as ethically unsound. 
Almost half of the sample thought there were times when it is acceptable to advise athletes about anti-doping (41.5\%) or nutritional advice (44.7\%) without training. The sample was split about the ethicality of working with athletes with an ADRV recorded against them, with 39.4\% declaring it "unsound" and 35.0\% "sound". There was also some question over whether talking about athlete doping with other ASP was ethically sound; while 53.8\% declared it "unsound", $23.1 \%$ indicated it was sometimes appropriate. In contrast to $96.1 \%$ of respondents indicating they would never support performance enhancing drug use to facilitate recovery (see Table 3), 15.8\% reported there might be circumstances that did make it ethical. Finally, a minority of $19.5 \%$ indicated that publicly claiming to support anti-doping was ethically unsound.

Kruskal-Wallis testing of the ethicality items revealed variation by support role $(\mathrm{p}<0.05)$. Rates are reported as being potentially sound (aggregate of "unsound, with exceptions" to "sound"). The ambiguity in whether it was ethically sound to refuse work with an athlete who had an ADRV recorded against them saw variation across support roles. While most were small exchanges in distributions, the main effect was seen between coaches (46/53) indicating it was ethically sound to refuse compared with sports trainers (18/30) reporting it as unsound more often. Psychologists (3/6) indicated it was ethically sound to work with an athlete who thinks doping is okay in contrast with every other support role. Coaches were more comfortable giving dietary advice without training (33/54), followed by family and friends (9/17). Working with athletes who use anabolic steroids was generally seen as ethically unsound, with sports physicians (2/5) and psychologists (5/6) reporting more variation. Reporting an athlete who was doping was seen to be ethically sound by all administrators (27/27), nutritionists (6/6) and physiotherapists (9/9). Coaches (50/53) and trainers (27/30) reported it was ethically sound slightly less frequently. Given the dominance of responding at ethically "sound", it is notable that $3 / 5$ sports physicians, $9 / 16$ family and friends and 4/6 psychologists rated reporting as "unsound with exceptions" to "sound with exceptions". The acceptability of asking for testimonials about support for anti-doping was rejected by all psychologists $(0 / 6)$ in the sample. Coaches $(38 / 50)$ and physiotherapists $(5 / 9)$ were more likely to indicate there may be situations where such actions were justified. Finally, advising athletes about drug testing without proper training was more likely to be considered ethical under some situations by coaches (25/52), family and friends (7/17) and administrators $(13 / 28)$ compared with nutritionists $(1 / 6)$, trainers $(4 / 30)$, physicians $(1 / 5)$ or psychologists $(2 / 6)$. 


\section{Attitude}

ANOVA indicated no variation by support role in attitude towards performance enhancement in sport as measured by the PEAS ${ }^{1}$. With a range of 17-85 (higher scores reflect a pro-doping attitude), the average score of $43.0(\mathrm{SD}=5.0, \mathrm{n}=147)$ was below the midpoint of 51 (total sample 95CI: $(42.1,43.9))$. This indicates that Australian ASP have a slightly negative attitude towards performance enhancement in sport.

\section{Regression of Knowledge}

An exploratory forward stepwise linear regression using knowledge as the dependent variable was employed to determine if there were any relationships in the data. Independent variables were included on a pragmatic basis; no ethical behaviour or soundness items were included following the sample size to predictor ratio rule (Tabachnik \& Fidell, 2007). The independent variables included were gender, age, support role (dummy coded), highest level of support (dummy coded as for Table 1), support experience and PEAS score. After casewise deletion (valid $n=108)$ three steps identified a significant model $\left(\mathrm{F}_{3,107}=27.07\right.$, $\mathrm{p}<0.01$, Adj. $\left.\mathrm{R}^{2}=0.42\right)$, baseline knowledge $(\mathrm{B}=24.76, \mathrm{p}<0.01)$ was adjusted up by being a sports physician $(B=3.10, \beta=0.38, p<0.01)$ at the senior elite level $(B=2.21, \beta=0.35, p<0.01)$ and years experience $(B=0.07, \beta=0.22, p<0.01)$. The regression suggests the average population knowledge is $70.7 \%(24.76 / 35)$. The effect of being a sports physician increases total knowledge score by $8.8 \%(3.10 / 35)$. Having worked at the senior elite level also has an effect $(6.3 \%)$. Knowledge appears to gain slightly (1 point) after approximately 15 years of experience. For example, a senior elite sports physician with 15 years experience would typically score around $89 \%(31 / 35)$ compared to $70 \%$ for other ASP.

\section{Discussion}

Exploration of Australian ASP knowledge about anti-doping, and their ethics and attitudes towards doping showed variation by support role. Compared to sports physicians, some ASP had significantly lower levels of knowledge. Ethical behaviour around anti-doping showed some areas of concern (e.g. ignoring unethical behaviour), especially by support role (e.g. provision of untrained dietary advice). Ethical soundness pointed to divisions around what was considered appropriate, with a minority of ASP willing to make ethical exceptions around doping. Taken together, the practice of anti-doping by ASP appears to be far less certain than anti-doping agencies, policy writers or commentators may expect, with ASP

\footnotetext{
${ }^{1}$ Items 7, 8, 10 and 13 were reverse scored.
} 
willing to overlook some practices and in doubt about the "rightness" of others. Australian ASP took a generally negative attitude towards performance enhancement in sport. The exploratory regression suggested that experienced senior elite sports physicians were the most knowledgeable of all ASP. These results have the capacity to inform anti-doping education policy to direct resources to where they will have best effect; for example, targeting non-medical ASP. While the emergent biases in the data restrict the generalisability of results, these biases provide valuable information in addressing ASP education around their anti-doping obligations.

\section{Sample Limitations and Bias}

The sample was biased, caused in part by some professional organisations refusing to permit access to members for administration of the survey. The reason for this emerged from correspondence with professional organisations and verbal feedback from conference respondents and non-respondents. Some organisations felt the survey topic was irrelevant to their members, despite their members falling under the WADC definition of ASP. This surprised the research team given the strict liability nature of the WADC and the severity of sanctions. One explanation for the apathetic response to the survey may be the absence a case where an ASP has been sanctioned in Australia. Unlike other jurisdictions with an established record of sanctioning ASP since 2009 (e.g. Canada, the United Kingdom and the United States), a review of the Australian Sports Anti-Doping Authority (ASADA) media releases back to 2009 demonstrates no similar sanction cases in Australia. It remains to be seen whether sanctioning ASP for failing to meet obligations under the WADC would have an effect on ASP engagement with anti-doping in Australia. The dismissal of Matt White as Head Coach at Cycling Australia, after his doping admission in the Lance Armstrong case (ABC 2012), could bring greater public attention to the no-tolerance position of national sports bodies in relation to doping in sport. However, even if White is sanctioned for doping as an athlete, this is different to being sanctioned in an ASP role. In sum, while the explanation for the observed pattern of responding is unclear, it points to apathy or lack of awareness among organisational and individual ASP at this stage with regards to anti-doping that needs to be overcome in order to ensure ASP do not commit an inadvertent ADRV.

The completion rate gives two core pieces of information. The first is that the questionnaire design was onerous, particularly the adaptation of Dawson et al (2001). Combined with the perceived irrelevance of the survey by members of some professional bodies, this meant that respondents were unwilling to work their way through the survey to the end. This may have 
been averted with pilot testing, and informs any future replication of the current project. The second piece of information to be gleaned from the completion rates was an indication of where anti-doping was seen to be more and less valent. The high completion rate among sports physicians and sports trainers suggested that these groups are more engaged with anti-doping and willing to complete a questionnaire on the topic. Notably, the groups least engaged were those involved with junior elite sport, especially family members. This is concerning as junior elite sport represents the conduit for senior elite sport. Failure to engage ASP at this stage may point to a potential barrier to inculcate junior elite athletes with the values promoted by the anti-doping policy. Moreover, a lack of engagement with family members of junior elite athletes represents a key vulnerability to doping because parents represent one of the groups likely to lead adolescent athletes towards doping (Laure \& Binsinger, 2005). Therefore, engaging parents in anti-doping education helps to mitigate the risk of an ADRV due to lack of awareness (which could manifest itself through a sanction to the ASP and the junior athlete caught up in the case). Thus, the pattern of incomplete responding suggests a need for stronger engagement with junior elite ASP and parents.

Analysis of complete and incomplete response demographics points to the typical respondent being a senior and experienced ASP engaged with anti-doping policy and practices. In terms of knowledge, the direction of bias in the sample means that the results apply to the right tail of the distribution. That is, the population scores are probably lower than those reported here. In terms of ethicality, the bias has probably overestimated the frequency of behaviour that supports anti-doping, and the perceived soundness of those behaviours. That is, an unbiased sample would probably see more diversity in responses, even if the distributions retained the same shape. In terms of attitude, the bias in the data means the population is probably higher than those reported here; that is, a more neutral or slightly positive attitude towards performance enhancement in sport. The results must be interpreted with these biases in mind.

\section{Knowledge}

Where the sample scored an average 27.7/35 (79\%) on the knowledge test, the bias in the sample suggests the population average would be as low as 63\% (one tailed 95CI (22.02, 27.70)). The sample was best at identifying ADRV, with equal performance across all other categories with the exception of ASP obligations. Applying the one-tailed test for bias to the questions specifically probing ASP obligations, the accuracy rate could be as low as $27 \%$ (one tailed 95CI $(1.76,3.10)$ ). Ironically, $96.5 \%$ of ASP correctly identified it was their responsibility to be familiar with the WADC. ASP were less familiar with the details of those 
responsibilities in terms of how reporting reduces sanctions (37.1\%), sanctions around ASP doping possession (36.2\%), their role in promoting anti-doping to athletes $(39.0 \%)$, and entering ineligible athletes in competition (26.6\%). These results suggest ASP have a reasonable grasp of the overall anti-doping system as it applies to athletes, but only an intuitive sense of their own obligations. With an average of two ASP-specific items incorrect and the bias pointing to a potential third, ASP appear to lack the depth of detail to avoid behaviours that may attract sanctions. It is up to policy makers to decide whether the apparent knowledge rate is acceptable.

The variation in knowledge by ASP role pointed to where education has been strong and can be improved. Sports physicians were clearly more knowledgeable than any other group and this suggests that the professional development used to raise sports physician knowledge of the WADC could be replicated for other ASP. Having said this, earlier studies, which have examined sports physicians' knowledge of anti-doping, have exposed a lack of awareness and a request for further professional development in this area (Backhouse \& McKenna, 2011). Therefore it seems that ASP as a whole need to be carefully targeted in future anti-doping efforts. For example, sports administrators and coaches were unaware of the processes underlying substance and method prohibition (i.e., the role of the spirit of sport in substance and method prohibition). Sports trainers demonstrated gaps in their knowledge of sample collection procedures, particularly in relation to sample provision and athletes rights and responsibilities following notification. The lowest scoring group, family and friends, need additional support on the roles governing substance and method use; fewer than half were able to identify when new prohibited lists were published and only 1 in 3 were aware of the current status of caffeine on the prohibited list. The implication of the results is that expanding the reach of anti-doping education beyond medical professionals to other ASP would theoretically raise the average level of knowledge to best practice. It would thus reduce the risk to ASP, to the junior athletes under their care/supervision, and provide greater opportunity to promote and reinforce the ethical values of doping-free sport. However, as Backhouse \& McKenna (2011) assert, even this substantial effort may be too little if this support network do not perceive this issue to be relevant to them. According to the principles of Adult Learning Theory (Knowles, 1980), anti-doping education should be 'relevancy oriented'; that is, to the context within which the ASP operate if learning is to take place.

\section{Ethical Behaviour and Soundness}

Following the bias in the sample, the measures of ethical behaviour and soundness yielded 
insights into how ASP engage with anti-doping. The majority observed a lack of support for new ASP in relation to anti-doping. The lack of support may be indicative of the organisational malaise suggested by some institutional responses to the survey, and sends a message to new ASP that anti-doping is to be given a lower priority relative to other ASP duties. This may be borne out by the failure of ASP to interact with each other on this issue, robbing them of the opportunity to learn from collective experience (sharing stories). Notably, this contrasts sharply with the majority who say it is ethically unsound to leave ASP without support understanding anti-doping. Part of the reason for this may extend from the $20-40 \%$ of ASP providing uneducated and uniformed advice in relation to the WADC, anti-doping activities or drug testing, with the majority of ASP seeing such practices as ethically unsound. More pragmatically, the five year ban of a Canadian sports trainer for giving a minor a diuretic (CCES, 2012) demonstrates the consequences of ASP giving advice without understanding their anti-doping obligation. Even with the bias in the sample, these results suggest a stronger engagement is needed to support Australian ASP understand and meet their anti-doping obligations.

There was a non-trivial minority of ASP for whom ethical behaviour was of little or no concern. This minority was characterised by their ignoring of unethical behaviour of other ASP, that such behaviour was ethical in at least some circumstances, and reporting ethical exceptions to reporting ASP complicit in an ADRV. This kind of ethical behaviour accords with Dawson et al's (2001) observations of Australian fitness professionals' confusion about ethical issues in their practice; the professionals were simply ill equipped to make judgements about the acceptability of certain behaviours. Part of the problem for anti-doping may be the lack of clarity as to the moral basis for anti-doping. The Spirit of Sport outlines 11 values that define the integrity of sport, and what makes sport protecting (WADA, 2009). However, there is no explanation of what any of these values means, leaving them open to reinterpretation (Mazanov et al., 2012). Reinterpretations may confuse what is "right" when it comes to doping (e.g. Savulescu et al., 2004). As a consequence, ASP may have to rely on their professional ethic (e.g. medicine and psychology) aligned with accreditation, if they have one. A stronger and clearer case for the moral basis of anti-doping may help overcome this problem (Loland \& Hoppeler, 2012; Mazanov \& Connor, 2010). Alternatively, developing a stronger set of professional ethics for other ASP roles (e.g. coaches, administrators and trainers) may help to mitigate this risk. 


\section{Attitudes}

ASP tended towards a homogeneous negative attitude to doping in sport. However, inspection of item frequencies suggested a consistent minority of 5-10\% who seem to take a different view on doping (middle-ground or positive attitude), which is likely to be larger in the population than in the current biased sample. This minority may be reacting to the social influences of sport, surrendering to the way sport is currently structured (Connor, 2009). In particular, between one-quarter and two-thirds of ASP noted selection and sponsorship make doping an unavoidable part of sport. This provides further insight into the content of antidoping education programmes as the focus on compliance means little opportunity to explore other risk factors for doping use.

\section{Predictors of Knowledge}

The exploratory regression indicated that physicians providing support to senior elite athletes for 15 years or more knew more about anti-doping than any other ASP group. The effect of being a physician or providing support to senior elite athletes was marked. This suggests that there may be something about the professional development of these groups that make them more knowledgeable. For example, sports physician knowledge may extend from advanced education in pharmacology and clinical ethics. Elite ASP may develop their knowledge through ongoing contact with anti-doping organisations, such as involvement with testing or out-of-competition testing administration. Determining what works for these roles could improve anti-doping education for ASP more broadly. The length of time for experience to impact on knowledge is both positive and negative. In a positive sense, baseline knowledge changes very little over time, possibly due to the principles of anti-doping changing very little since the inception of WADA and formalisation of the WADC. In a negative sense, there appears to be little increase in knowledge of anti-doping even with significant experience. This reinforces the need for ongoing education of ASP around anti-doping no matter how experiences they are.

\section{Implications and Future Research}

While Australian ASP appear to have at least passing familiarity with their obligations under the WADC, changes are needed to promote engagement with anti-doping as an important part of the ASP role. For example, engagement may be strengthened by incorporating anti-doping into induction packages for ASP, especially family of junior elite athletes. This can normalise anti-doping and makes it easier and more acceptable to talk about anti-doping. A core part of this might be to provide a stronger ethical component of the education, explaining the moral 
basis for anti-doping such that ASP can make judgements about the "rightness" of their behaviour relative to a set of defined values.

This project is necessarily confined to the questions in the survey. For example, observing that sports physicians and providing support at the senior elite level improves knowledge fails to give insight into how either experience achieves this; it could come through advanced education or simple exposure. Equally, the suggestion from the results that ASP make trade offs between professional and anti-doping obligations needs to be clarified. The next step is to use qualitative methods to explore the context within which ASP experience anti-doping policy and practices in Australia.

\section{Perspectives}

Athlete support personnel (ASP) awareness of and compliance with the World Anti-Doping Code (WADC) is necessary for sports medicine and allied sports health providers to avoid sanction. Consistent with previous research, sports medicine (Backhouse \& McKenna, 2011) and other support personnel (Backhouse \& McKenna, 2012) are at risk of sanction by gaps in the awareness and therefore compliance with their WADC obligations. Given awareness and compliance are the responsibility of ASP under the WADC, sports medicine and allied providers need to do more to ensure they knowledgeable about anti-doping. ASP also need to be more aware and concerned about the ethical practices of colleagues, both in terms of practicing within their field and anti-doping related behaviours. 
Acknowledgements: This project was funded by the Australian Government through the Anti-Doping Research Program (ADRP). The authors thank the ADRP for their support, as well as Sports Medicine Australia, the national sports organisations and the many support personnel who so generously gave of their time towards this project. 


\section{References}

ABC: CA sacks Matt White after doping confession [Internet]. Sydney, Australia: Australian Broadcasting Commission; 2012 October 17 [cited 2012 Oct 19]. Available from: http://www.abc.net.au/news/2012-10-17/ca-sacks-white-after-dopingconfession/4318886.

Amos A, Fridman S. Drugs in sport: The legal issues. In: J Mazanov, ed. Towards a Social Science of Drugs in Sport. Oxon, UK: Routledge, 2012 84-102.

Backhouse SH, McKenna J. Doping in sport: A review of medical practitioners' knowledge, attitudes and beliefs. Int J Drug Policy 2011: 22: 198-202.

Backhouse SH, McKenna J. Reviewing coaches' knowledge, attitudes and beliefs regarding doping in sport. Int J Sports Sci Coaching 2012: 7: 167-175.

CCES. Quebec trainer receives five-year ban for trafficking and administration [Internet]. Ottawa, Canada: Canadian Centre for Ethics in Sport; 2012 February 7 [cited 2012 July 10] Available from: http://www.cces.ca/en/news-188-quebec-trainer-receives-five-yearban-for.

Connor J. Towards a sociology of drugs in sport. Sport in Society 2009: 12: 327-343.

Dawson A, Anderson MB, Hemphill D. The ethical beliefs and behaviours of Victorian fitness professionals. J Sci Med Sport 2001: 4: 266-282.

Dubin, C. L. (1990). Commission of Inquiry into the Use of Drugs and Banned Practices Intended to Increase Athlete Performance. Ottawa, Canada: Canadian Government Publishing Centre.

Guardian. Carlos Queiroz's ban for disrupting anti-doping test lifted on appeal [Internet]. London, UK: The Guardian; 2011 March 23 [cited 2012 July 12]. Available from: http://www.guardian.co.uk/football/2011/mar/23/carlos-queiroz-portugal-ban-lifted.

Gucciardi DF, Jalleh G, Donovan R. Does social desirability influence the relationship between doping attitudes and doping susceptibility in athletes? Psychol Sport Exerc 2010: 11: 479-486.

Hoberman J. How drug testing fails: The politics of doping control. In Wilson W, Derse E, eds. Doping in Elite Sport: The Politics of Drugs in the Olympic Movement. Champaign, IL: Human Kinetics 2001: 241-274. 
Knowles MS. The Modern Practice of Adult Education: From Pedagogy to Androgogy. $2^{\text {nd }}$ ed. New York, NY: Cambridge Books; 1980

Laure P, Binsinger, C. Adolescent athletes and the demand and supply of drugs to improve their performance. J Sports Sci Med 2005: 4: 272-277.

Loland S, Hoppeler H. Justifying anti-doping: The fair opportunity principle and the biology of performance enhancement. Eur J Sports Sci 2012: 12: 347-353.

Mazanov J. Drug use and abuse by athletes. In Hanrahan SJ, Anderson MB, eds. Routledge Handbook of Applied Sport Psychology. Oxon, UK: Routledge 2010: 214-223.

Mazanov J, Connor J. Rethinking the management of drugs in sport. Int J Sports Policy 2010: 2: 49-63.

Mazanov J, Huybers T. An empirical model of athlete decisions to use performance enhancing drugs: Qualitative evidence. Qual Res Sport Exerc 2010: 2: 385-402.

Mazanov J, Connor J, Hemphill D. The 2009 World Anti-Doping Code and medical support personnel. SportHealth 2009: 27: 11-13.

Mazanov J, Huybers T, Connor J. Prioritising health in anti-doping: What Australians think. J Sci Med Sport 2012: 15: 381-385.

Petroczi A, Aidman E. Measuring explicit attitude toward doping: A review of the psychometric properties of the Performance Enhancing Attitude Scale. Psychol Sport Exerc 2009; 10: 390-396.

Savulescu J, Foddy B, Clayton M. Why we should allow performance enhancing drugs in sport. Brit J Sports Med 2004: 38: 666-670.

Smith ACT, Stewart B. Drug policy in sport: Hidden assumptions and inherent contradictions. Drug Alc Rev 2008: 27: 123-129.

Tabachnik, B. G. \& Fidell, L. S. (2007). Using Multivariate Statistics ( $5^{\text {th }}$ Ed). Boston, MA: Pearson Education, Inc.

USADA. U.S. Track \& Field Coach, Raymond Stewart, receives lifetime suspension [Internet]. Colorado Springs, CO: USADA. 2010 June 28 [cited 2012 July 12]. Available from http://www.usada.org/default.asp?uid=2805.

USADA. International track and field sports agency and event manager, Mark Block, receives 10-year suspension from independent arbitration panel based on participation in BALCO drug conspiracy [Internet]. Colorado Springs, CO: USADA; 2011 March 18 [cited 2012 July 12]. Available from: http://www.usada.org/default.asp?uid=3333. 
USADA. US Postal Service Pro Cycling Team Investigation [Internet]. Colorado Springs (CO): USADA; 2012a October 10 [cited 2012 October 12]. Available from http://cyclinginvestigation.usada.org/

USADA. Members of the United States Postal Service Pro-Cycling Team doping conspiracy, Dr. Garcia Del Moral, Dr. Ferrari and Trainer Marti receive lifetime bans for doping violations [Internet]. Colorado Springs (CO): USADA; 2012b July 10 [cited 2012 July 12]. Available from http://www.usada.org/media/sanction-usps 7102012.

UK Anti-Doping. Three former Hull RLFC employees banned for anti-doping rule violations [Internet]. London, UK: UK Anti-Doping; 2011 December 29 [cited 2012 July 10]. Available from http://www.ukad.org.uk/news/article/three-former-hull-rlfc-employeesbanned-for-anti-doping-rule-violations

WADA. World Anti-Doping Code. Montreal, Canada: World Anti-Doping Agency; 2009.

WADA. World Anti-Doping Code Draft Version 2.0 2015. Montreal, Canada: World AntiDoping Agency; 2012. 